\title{
The T1-T2 study: evolution of aerosol properties downwind of Mexico City
}

\author{
J. C. Doran ${ }^{1}$, J. C. Barnard ${ }^{1}$, W. P. Arnott ${ }^{2}$, R. Cary $^{3}$, R. Coulter ${ }^{4}$, J. D. Fast ${ }^{1}$, E. I. Kassianov ${ }^{1}$, L. Kleinman ${ }^{5}$, \\ N. S. Laulainen ${ }^{1}$, T. Martin ${ }^{4}$, G. Paredes-Miranda ${ }^{2}$, M. S. Pekour ${ }^{1}$, W. J. Shaw ${ }^{1}$, D. F. Smith ${ }^{3}$, S. R. Springston , and $^{5}$ \\ X.-Y. Yu ${ }^{1}$ \\ ${ }^{1}$ Pacific Northwest National Laboratory, Richland, WA, USA \\ ${ }^{2}$ Desert Research Institute, Reno, NV, USA \\ ${ }^{3}$ Sunset Laboratory, Inc., Tigard, OR, USA \\ ${ }^{4}$ Argonne National Laboratory, Argonne, IL, USA \\ ${ }^{5}$ Brookhaven National Laboratory, Upton, NY, USA
}

Received: 6 November 2006 - Published in Atmos. Chem. Phys. Discuss.: 12 December 2006

Revised: 22 February 2007 - Accepted: 15 March 2007 - Published: 23 March 2007

\begin{abstract}
As part of a major atmospheric chemistry and aerosol field program carried out in March 2006, a study was conducted in the area to the north and northeast of Mexico City to investigate the evolution of aerosols and their associated optical properties in the first few hours after their emission. The focus of the T1-T2 aerosol study was to investigate changes in the specific absorption $\alpha_{\mathrm{ABS}}$ (absorption per unit mass, with unit of $\mathrm{m}^{2} \mathrm{~g}^{-1}$ ) of black carbon as it aged and became coated with compounds such as sulfate and organic carbon, evolving from an external to an internal mixture. Such evolution has been reported in previous studies. The T1 site was located just to the north of the Mexico City metropolitan area; the T2 site was situated approximately $35 \mathrm{~km}$ farther to the northeast. Nephelometers, particle soot absorption photometers, photoacoustic absorption spectrometers, and organic and elemental carbon analyzers were used to measure the optical properties of the aerosols and the carbon concentrations at each of the sites. Radar wind profilers and radiosonde systems helped to characterize the meteorology and to identify periods when transport from Mexico City over T1 and T2 occurred. Organic and elemental carbon concentrations at $\mathrm{T} 1$ showed diurnal cycles reflecting the nocturnal and early morning buildup from nearby sources, while concentrations at $\mathrm{T} 2$ appeared to be more affected by transport from Mexico City. Specific absorption during transport periods was lower than during other times, consistent with the likelihood of fresher emissions being found when the winds blew from Mexico City over T1 and T2. The spe-
\end{abstract}

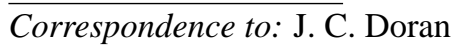

(christopher.doran@pnl.gov) cific absorption at $\mathrm{T} 2$ was larger than at $\mathrm{T} 1$, which is also consistent with the expectation of more aged particles with encapsulated black carbon being found at the more distant location. In situ measurements of single scattering albedo with an aircraft and a ground station showed general agreement with column-averaged values derived from rotating shadowband radiometer data, although some differences were found that may be related to boundary-layer evolution.

\section{Introduction}

The MILAGRO (Megacity Initiative: Local and Global Research Observations; http://www.eol.ucar.edu/projects/ milagro/) field campaign was designed to follow the urban plume originating in Mexico City in order to study the evolution of the properties of trace gases and aerosols as they drifted downwind from a megacity. The study was conducted over multiple scales, ranging from ground-based investigations centered in the Mexico City metropolitan area to aircraft sampling over distances of hundreds of kilometers. A major component of the MILAGRO campaign was the MAX-MEX experiment (Megacity Aerosol Experiment in Mexico City; http://www.asp.bnl.gov/MAX-Mex.html), which focused on measurements within, over, and a few tens of kilometers downwind from Mexico City. MAX-MEX was supported by the U.S. Department of Energy through its Atmospheric Sciences Program. In this paper we describe some aspects of one element of the MAX-MEX experiment that we refer to as the T1-T2 study.

Published by Copernicus GmbH on behalf of the European Geosciences Union. 
The T1-T2 study was motivated by the desire to investigate the evolution of aerosols and their associated optical properties in the first few hours after their formation. We hypothesized that the shift from an externally mixed state characteristic of fresh emissions to an internally mixed one would result in significant modifications to the optical properties of aerosols as they were advected downstream from Mexico City. Evidence for changes in aerosol composition due to aging in the Mexico City area has been found by other investigators (e.g., Baumgardner et al., 2000; Johnson et al., 2005). We were particularly interested in changes in the mass absorption efficiency or specific absorption $\alpha_{\mathrm{ABS}}$ (absorption per unit mass, with unit of $\mathrm{m}^{2} \mathrm{~g}^{-1}$ ) of black carbon (BC) because of its potential importance for climate change. The specific absorption is one of two key parameters that determine the magnitude of the aerosol forcing by $\mathrm{BC}$, the other being the atmospheric burden (Chung and Seinfeld, 2002; Sato et al., 2003). In this paper we will use the terms black carbon and elemental carbon (EC) interchangeably, but we note here that Andreae and Gelencsér (2006) warn that the term "black carbon" has been used somewhat carelessly in the literature. For the moment we will not deal with this difficulty but will return to it when we discuss our absorption measurements in Sect. 5.

In the past, field estimates of the specific absorption of black carbon have varied by an order of magnitude, ranging from $2 \mathrm{~m}^{2} \mathrm{~g}^{-1}$ to $25 \mathrm{~m}^{2} \mathrm{~g}^{-1}$ at $\sim 500 \mathrm{~nm}$. (e.g., Waggoner et al., 1981; Horvath, 1993; Liousse et al., 1993; Petzold et al., 1997; Penner et al., 1998; Moosmüller, 1998; Marley et al., 2001; Baumgartner, 2002; Arnott et al., 2003; Schnaiter et al., 2003; Schuster et al., 2005; Mikhailov et al., 2006). While BC is normally assumed to be present as an external mixture close to the source (e.g., Mallet et al., 2003; Jacobson and Seinfeld, 2004), processes such as heterocoagulation and condensation can alter the mixing state as the particles age (e.g., Jacobson, 2001). Such processes likely have contributed to the order of magnitude differences in the estimates of $\alpha_{\mathrm{ABS}}$ noted above. Recently, Bond and Bergstrom (2006) suggested that freshly emitted, uncoated soot particles have a value of $\alpha_{\mathrm{ABS}}=7.5 \pm 1.2 \mathrm{~m}^{2} \mathrm{~g}^{-1}$ at $550 \mathrm{~nm}$. This "uncoated" value will increase as the particles age and become coated, e.g., with substances such as sulfate or organic carbon, but the rates at which aging occurs and direct observations of the change in $\alpha_{\mathrm{ABS}}$ as this occurs downstream from a source have been difficult to determine in the field. In contrast, the theoretical study of Fuller et al. (1999) suggests that $\alpha_{\mathrm{ABS}}$ is unlikely to exceed $10 \mathrm{~m}^{2} \mathrm{~g}^{-1}$ unless most of the BC is encapsulated in aerosol distributions whose geometric mean radius is greater than $0.06 \mu \mathrm{m}$. In light of these and other studies, we are led to ask: to what extent and at what rate does aging affect $\alpha_{\mathrm{ABS}}$ for BC-containing aerosols that were originally uncoated?

The campaign in the Mexico City area provided an opportunity to address this question by measuring values of $\alpha_{\mathrm{ABS}}$ at two or more locations, one relatively close to ma- jor sources of $\mathrm{BC}$ and one farther downstream. Unless an aerosol is somehow tagged to a specific source, the precise location and time of the formation, $\mathrm{t}_{0}$, of an aerosol over Mexico City is essentially impossible to determine after it has drifted downwind by a few kilometers. Once outside the primary source region, however, it is possible, at least in principle, to track air masses containing aerosols. Our approach was to measure aerosol properties at two sites downwind of the Mexico City urban area and to use meteorological measurements and modeling to determine periods when aerosols originating in Mexico City passed over the two sites. During those periods a segment of the urban plume can be assumed to arrive at the first downwind location at a time $t_{1}$ and at the second location at a time $\mathrm{t}_{2}$, thereby giving rise to the T1-T2 identifying label for this study. The differences in aerosol properties as a function of the time difference $t_{2}-t_{1}$ can then be studied.

In the remainder of this paper we describe the design of the T1-T2 study, compare some of the meteorological conditions found over the $\mathrm{T} 1$ and $\mathrm{T} 2$ sites, identify periods when the Mexico City plume was expected to flow over both sites, and present some preliminary comparisons of specific absorption and other aerosol properties at the two locations. More extensive and detailed comparisons, as well as analyses of results obtained at $\mathrm{T} 0$, will be the subjects of future papers.

\section{Study design}

The T1 site was located at Tecamac University at $19.703 \mathrm{~N}$ latitude and $98.982 \mathrm{~W}$ longitude, at an altitude of $2273 \mathrm{~m}$. This site is near built-up regions and a major highway and is just to the north of the main metropolitan area of Mexico City. Because the site is close to the city we expected it would frequently be affected by the urban plume drifting over the region. An analysis combining computer modeling, radar wind profiler and radiosonde data collected during the 1997 IMADA-AVER experiment (Doran et al., 1998), and rawinsonde data from 2002 and 2003 (http://mirage-mex.acd.ucar.edu/Documents/ MIRAGE-Mex_SOD_040324.pdf) indicated that, in the upper portions of the boundary layer and above, flows from Mexico City to the north, northeast, or northwest could be expected roughly $50 \%$ of the time during the month of March. Closer to the surface the winds tend to be lighter and less well organized. It was also estimated that winds throughout the depth of the boundary layer would carry the Mexico City urban plume to the north-northeast over the city of Pachuca between 20 and $30 \%$ of the time. Additional information about the meteorology encountered during the MILAGRO campaign will be published elsewhere.

Although the expected frequency of favorable wind directions was not as high as we might have wished, it was decided nonetheless that it would still be worthwhile to locate the T2 site in the general area of Pachuca. Accordingly, the 


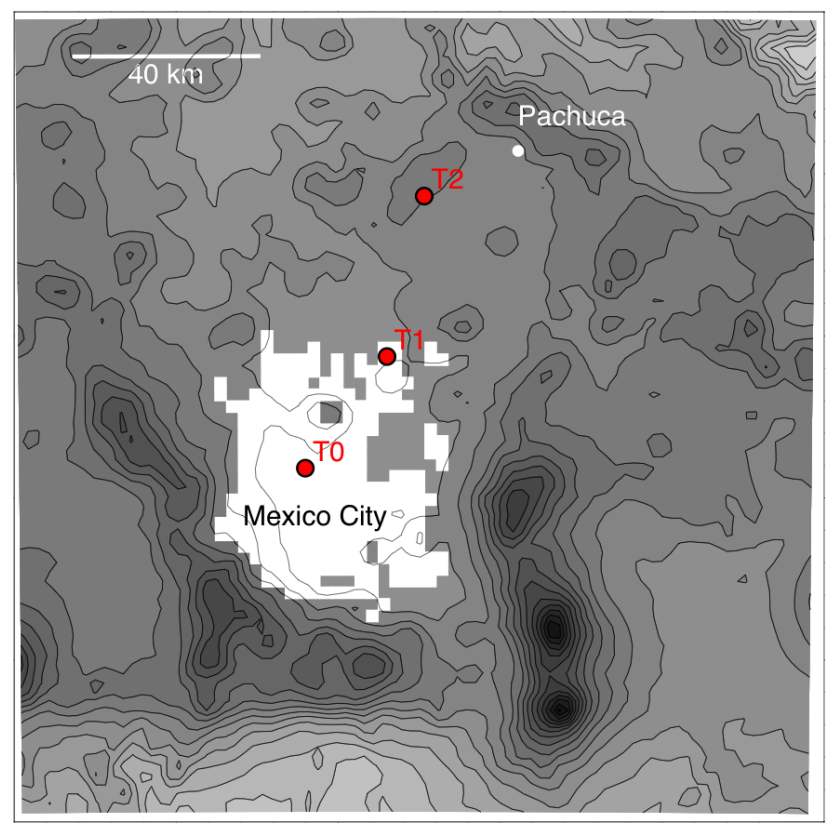

Fig. 1. Map of study area showing locations of $\mathrm{T} 1$ and $\mathrm{T} 2$ sites. Topography contour intervals are $200 \mathrm{~m}$.

T2 site was situated $35 \mathrm{~km}$ to the north-northeast of T1 at Rancho la Bisnaga, 20.010 N latitude and 98.909 W longitude, at an altitude of $2542 \mathrm{~m}$. The locations of these two sites are shown in Fig. 1. The region between T1 and T2 is much less densely developed than the Mexico City urban area. Some local sources of BC and other aerosols can be found between $\mathrm{T} 1$ and $\mathrm{T} 2$, primarily along the highway between Mexico City and Pachuca, but their impact was expected to be small compared to that of the urban plume originating in Mexico City. Also shown in Fig. 1 is the location of the Insituto Mexicano del Petróleo, labeled T0 in the figure, which was an observation site considered to be representative of the Mexico City metropolitan area.

The T1 site was one of the two major ground sites for the MILAGRO campaign, with investigators from approximately a dozen laboratories and universities making a wide range of meteorological, chemical, aerosol, and atmospheric radiation measurements. In contrast, the $\mathrm{T} 2$ site featured a much smaller number of investigators and instruments, consistent with the expected infrequency of urban plume passages over that location. In this paper we will consider data from pairs of instruments, with one of each pair located at both $\mathrm{T} 1$ and $\mathrm{T} 2$ : radar wind profilers, radiosondes, organic and elemental carbon (OCEC) analyzers, photoacoustic absorption spectrometers (PASs), 3-wavelength nephelometers, particle soot absorption photometers (PSAPs), and multifilter rotating shadowband radiometers (MFRSRs). Information about these instruments is provided below. In addition to these ground-based instruments, several aircraft made flights over $\mathrm{T} 1$ and $\mathrm{T} 2$ during the campaign. We will briefly dis-
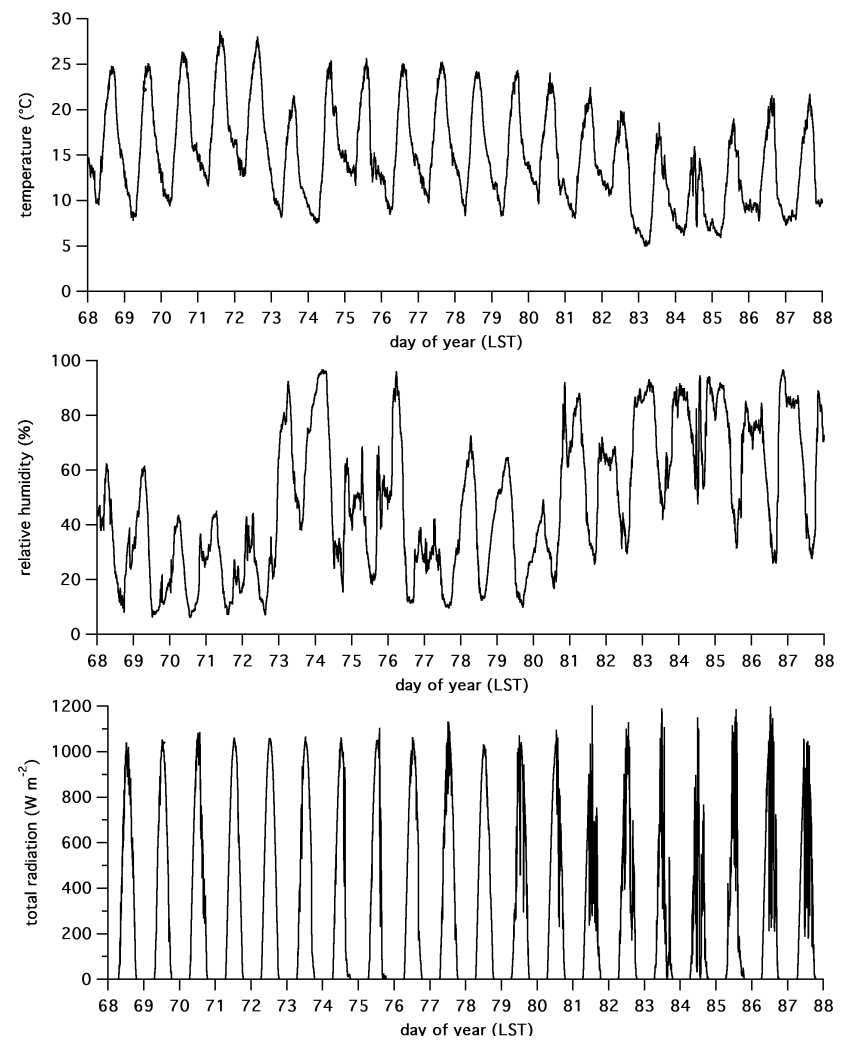

Fig. 2. Time series of temperature, humidity, and total solar radiation measured with surface instruments located at T2.

cuss some results from measurements with a nephelometer and PSAP on board DOE's Gulfstream-1 (G-1) aircraft taken during periods when the Mexico City plume was expected to drift over those sites.

Although some instruments were operational earlier, fullscale operations at T1 and T2 commenced approximately on day of year (DOY) 70 (11 March). Measurements at both sites continued from that time through DOY 87 (28 March). Figure 2 shows time series of temperature, humidity, and total solar radiation measured with surface instruments located at T2. The first two weeks of the measurement period were generally warmer, drier, and had less cloudiness than the last week. Rain showers occurred on a daily basis during the last week.

\section{Instruments}

The radar wind profilers (RWPs) used at T1 and T2 were $915 \mathrm{MHz}$ models manufactured by Vaisala. They were operated in a 5-beam mode with nominal 192-m range gates. We applied the NCAR Improved Moment Algorithm (Morse et al., 2002) to the moments data from the profilers to obtain 30-min average consensus winds. The radiosonde systems were Vaisala DigiCORA $^{\text {TM }}$ systems and used model RS-92 
sondes, also manufactured by Vaisala. The sondes released at T2 measured temperature and humidity while some of the sondes released at T1 also measured winds with a GPS system. On days when the G-1 was expected to fly in the vicinity of T1, up to five radiosondes were released there, nominally at 09:00, 11:00, 13:00, 15:00, and 17:00 local standard time (LST). If the anticipated G-1 flights included sampling in the $\mathrm{T} 2$ area, up to three additional sondes were launched at $\mathrm{T} 2$ at 11:00, 13:00, and 15:00 LST.

The OCEC analyzers were manufactured by Sunset Laboratory Inc., and are similar to the thermal-optical instrument described in Birch and Cary (1996). Samples collected on a quartz filter are volatilized under controlled conditions of temperature and processing gas mixtures. The process is used to differentiate between organic and elemental carbon, with an optical correction technique applied to correct for pyrolytically generated carbon. Sampling times were $45 \mathrm{~min}$ in length, with an additional $15 \mathrm{~min}$ allocated to analysis and cooling after each sampling period. The OCEC unit was calibrated on-site using external standard filters before ambient sampling. The external standard was analyzed in off-line mode. The data acquisition parameters were adjusted after the calibration to reflect the known OC/EC ratio. The estimated detection limit is $0.02 \mu \mathrm{gC} \mathrm{m}^{-3}$ and the estimated uncertainty of the OCEC measurement is $0.2 \mu \mathrm{gC} \mathrm{m}{ }^{-3}$. Quartz filters were changed every few days before a significant reduction in the intensity of the laser signal used for the optical corrections was observed. A blank sample was scheduled for midnight (LST) daily. We restricted our analyses to periods when the $\mathrm{OC}$ and $\mathrm{EC}$ concentrations were greater than or equal to $0.1 \mu \mathrm{gC} \mathrm{m}^{-3}$.

The PAS measures sound pressure produced by light absorption in an acoustic resonator and has been described by Arnott et al. (1999). The instruments at T1 and T2 operated at a wavelength of $870 \mathrm{~nm}$. Operation at $870 \mathrm{~nm}$ is advantageous because $\mathrm{BC}$ does absorb at this wavelength but the absorption of other atmospheric constituents such as dust and OC is quite weak (Jacobson, 1999; Sokolik and Toon, 1999; Sato et al., 2003; Kirchstetter et al., 2004). Average absorption values were computed every two minutes, and we combined absorption values averaged over 46-min periods with EC values from the OCEC analyzers to obtain estimates of the specific absorption of EC at T1 and T2.

The nephelometers (TSI 3563) and PSAPs (Radiance Research) at T1 and T2 were configured as parts of aerosol optical measurement systems developed by NOAA's Climate Modeling \& Diagnostics Laboratory (CMDL). Ambient air is diverted alternately through $1 \mu \mathrm{m}$ and $10 \mu \mathrm{m}$ impactors at 6-min intervals, and the humidity is controlled so that it is less than or equal to $40 \% \mathrm{RH}$ before the air is introduced into the nephleometer or PSAP. The nephelometers operated at three wavelengths: $450 \mathrm{~nm}, 550 \mathrm{~nm}$, and $700 \mathrm{~nm}$; the PSAPs also operated at three wavelengths: $470 \mathrm{~nm}, 530 \mathrm{~nm}$, and $660 \mathrm{~nm}$. Scattering and absorption measurements were averaged and recorded every minute. The nephelometer and PSAP on the G-1 operated at the same wavelengths as the surface units. Corrections to the PSAP absorption and the nephelometer scattering were carried out using the approach described by Bond et al. (1999) and Anderson and Ogren (1998). Additional information on the nephelometers and PSAPs can be found at the CMDL website http: //www.cmdl.noaa.gov/aero/instrumentation/instrum.html.

The MFRSRs (Harrison et al., 1994) measured the direct normal, diffuse horizontal, and total horizontal components of the broadband irradiances using a silicon detector, and these same components at six wavelengths $(415,500,615$, 673,870 , and $940 \mathrm{~nm}$ ) with an interference filter/silicon detector combination having a nominal passband of $10 \mathrm{~nm}$ at each wavelength. Data were averaged and recorded at 20$\mathrm{s}$ intervals. From these measurements, we can determine aerosol optical thickness, $\tau$. By applying the technique of Kassianov et al. (2005) it is also possible to determine the aerosol single scattering albedo, $\varpi_{0}$, and asymmetry parameter, g. In contrast to the aerosol quantities measured by our other surface instruments, these quantities should be considered as averages over the atmospheric column.

\section{Boundary-layer structure and winds}

Doran et al. (1998) found that on clear days the boundary layer (BL) in Mexico City during March typically grew slowly after sunrise (approximately 06:40 LST) to a depth on the order of $1000 \mathrm{~m}$ by 11:00 or 12:00 LST, after which it grew rapidly to heights of $3000 \mathrm{~m}$ or more in the next few hours. This behavior was observed at T1 during the MILAGRO campaign as well, although the heights tended to be somewhat smaller during this campaign, and the BL behavior at the $\mathrm{T} 1$ and $\mathrm{T} 2$ sites appeared to be similar. Figure 3 shows a comparison of BL depths estimated from potential temperature profiles measured with radiosondes at $\sim 11: 00$, 13:00, and 15:00 LST on days for which nearly simultaneous releases were made at the two sites. The regression line is given by $\mathrm{h} 2=0.90 \times \mathrm{h} 1+25 \mathrm{~m}$, with $R^{2}=0.89$, where $\mathrm{h} 1$ and $\mathrm{h} 2$ are the BL depths at $\mathrm{T} 1$ and $\mathrm{T} 2$, respectively. We have also compared boundary-layer depths at $\mathrm{T} 1$ and $\mathrm{T} 2$ by examining the signal-to-noise ratio of the reflected signals from the RWPs at the two sites (not shown). The agreement between the two sites is again reasonable $\left(R^{2}=0.90\right)$, with $\mathrm{h} 2=0.79 \times \mathrm{h} 1+260 \mathrm{~m}$. The similarity of the boundary layer depths at the two sites simplifies some aspects of the analysis. It makes plume trajectory analyses easier (see below) and it helps ensure that aircraft operations in the mixed layer at one site will also be in the mixed layer at the second site, providing the flight altitudes are not too different. Further information on boundary layer characteristics during the campaign will be the subject of other papers.

We were particularly interested in days when the winds were likely to blow the urban plume over both $\mathrm{T} 1$ and $\mathrm{T} 2$. A detailed analysis identifying times when this occurred will 
be carried out in the future using a mesoscale model that incorporates a data assimilation scheme, parameterizations of vertical mixing, and estimates of source locations in the Mexico City metropolitan area. For this initial analysis, however, we have simply used the wind data obtained from the RWP at T1 to calculate forward and back trajectories of air masses that passed over T1. Figure 4 shows examples of trajectories calculated at $1000 \mathrm{~m}$ above ground level (AGL) for daylight hours over a 20-day period. The most favorable conditions for T1-T2 transport are seen to have occurred on DOY 69, 77, 78, 79, and 83, (10, 18, 19, 20, and 24 March, respectively) with briefer periods of preferred wind directions occurring on several other days. On some days (e.g., DOY 81 [22 March]) the calculated trajectories showed the Mexico City plume traveled close to T2, and lateral spreading of the plume may well have resulted in some impact of Mexico City emissions on both T1 and T2. On other days (e.g., DOY 74 [14 March]), the trajectories show near-misses at T2 but the back trajectories at $\mathrm{T} 1$ suggest that the air mass traveling from $\mathrm{T} 1$ to $\mathrm{T} 2$ did not originate over the urban region. In some cases the wind directions exhibited substantial vertical shear (not shown), which makes interpretation of the plume transport problematic.

On many days, and especially on those with wind directions favorable for T1-T2 transport, the boundary layer was quite dry. For example, by 11:00 LST on each of DOY 70, 77,78 , and $79(10,18,19$, and 20 March) radiosonde soundings at $\mathrm{T} 1$ showed relative humidities in the boundary layer of $46 \%$ or less (usually much less), with similar values found from the T2 sondes. Above the boundary layer there was often a very dry layer that could extend over depths of hundreds of meters or more. Figure 5 shows an example of this feature. Hygroscopic growth of aerosols and the consequent effects on aerosol light scattering can be assumed to be essentially negligible under such dry conditions (Nemesure et al., 1995; Baumgardner and Clarke, 1998; Im et al., 2001; Redemann et al., 2001; Carrico et al., 2003; Markowicz et al., 2003). Thus, the optical properties of aerosols measured near the surface are likely to be similar to those aloft in a well-mixed boundary layer, which is advantageous for some radiative closure analyses.

\section{Results and discussion}

\subsection{OC and EC concentrations}

Figure 6 shows plots of the organic (OC) and elemental (EC) carbon concentrations at $\mathrm{T} 1$ and $\mathrm{T} 2$ as a function of time. At $\mathrm{T} 1$ there was often a strong diurnal variation in OC and EC concentrations during the first two weeks, with concentrations increasing during the nighttime hours and the largest values occurring in the morning hours around sunrise or shortly after. This behavior is consistent with the trapping of pollutants in the Mexico City area overnight and during

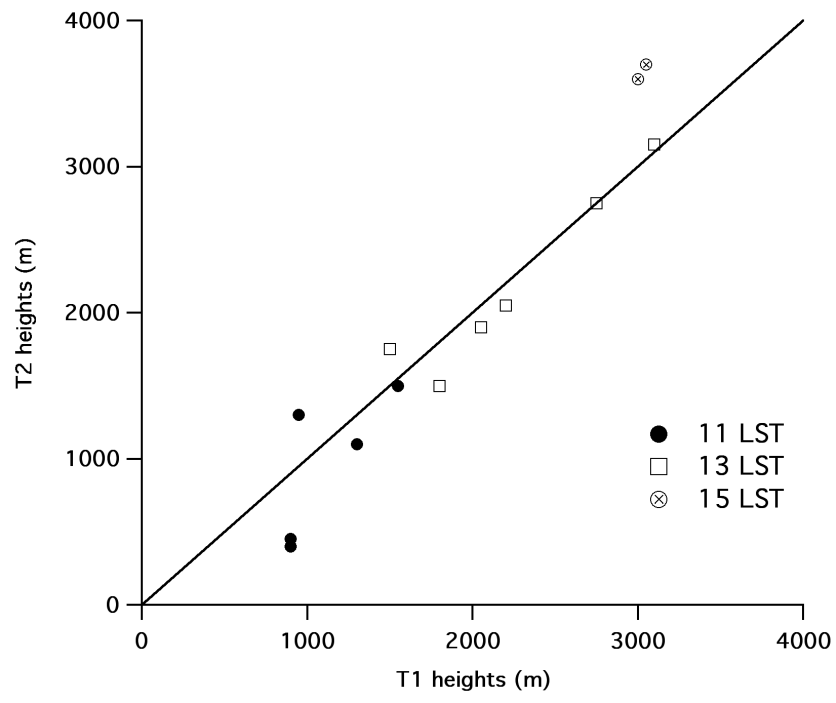

Fig. 3. Comparison of boundary-layer depths at $\mathrm{T} 1$ and $\mathrm{T} 2$ estimated from potential temperature profiles measured with radiosondes at $\sim 11: 00,13: 00$, and 15:00 LST on days for which nearly simultaneous releases were made at the two sites: 11:00 LST (DOY 68, 74, 77-78), 13:00 LST (DOY 68, 69, 76-79), and 15:00 LST (DOY 68 and 79).

the morning hours in a shallow surface layer before the rapid growth of the mixed layer commences in the late morning. Although the boundary layer structure and evolution at T2 were similar to those at $\mathrm{T} 1$, the $\mathrm{OC}$ and $\mathrm{EC}$ behavior at $\mathrm{T} 2$ was much less regular; there were often multiple peaks during a 24-h period, and mid- to late-afternoon peaks were common. No significant accumulations of pollutants, comparable to what was found at T1, developed overnight at T2. This was expected, given the absence of local sources in the area around and immediately upwind of T2.

Transport from Mexico City to T2 appears to account for a substantial fraction of the variations in OC and EC concentrations at T2. OC and EC concentrations were generally lowest at both sites during the last week of the campaign when the weather conditions were most unsettled and there were periods of rain. On days with the most favorable wind directions for T1-T2 transport (DOY 69, 77, 78, and $79(10,18,19$, and $20 \mathrm{March})$ ), both the OC and EC values at T2 tended to reach higher values than on other occasions, although DOY 70, 71, and 81 (11, 12 and 22 March) also have elevated readings. At $\mathrm{T} 1$, which was considerably closer to the local and Mexico City sources than T2, the carbon concentrations showed less sensitivity to wind directions.

DOY 83 (24 March) has been identified as a transport day but shows some unusual features. The OC and EC concentrations at T1 were low throughout the night, but the OC values were considerably higher during the day while the EC values were not. At T2, OC and EC were low at night but both increased substantially shortly after sunrise. Rain fell at $\mathrm{T} 1$ and $\mathrm{T} 2$ just after sunset the previous night and during 

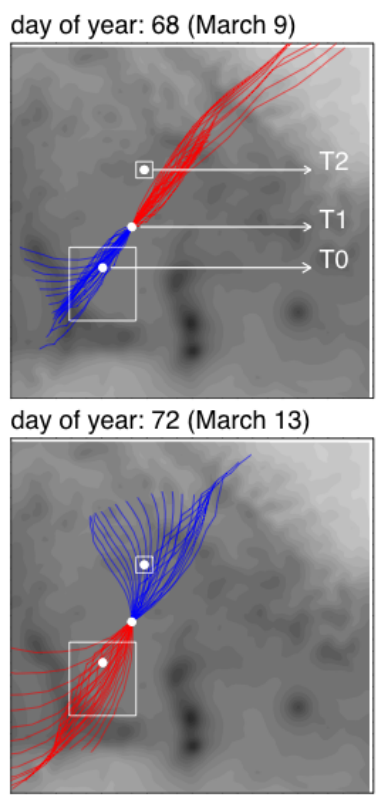

day of year: 76 (March 17)

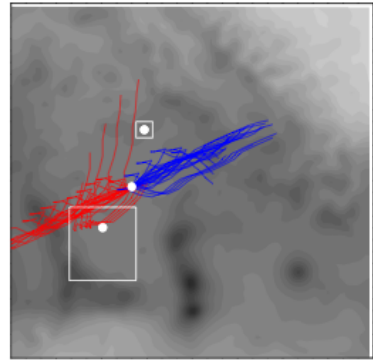

day of year: 80 (March 21)

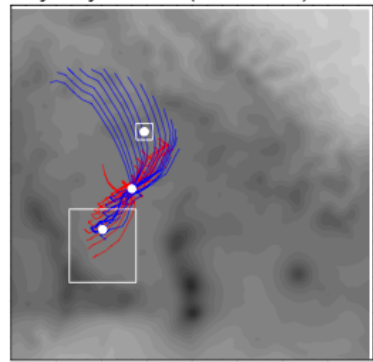

day of year: 84 (March 25)

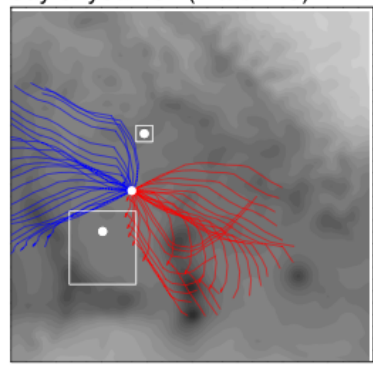

day of year: 69 (March 10)

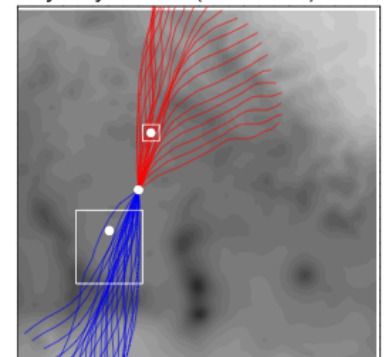

day of year: 73 (March 14)

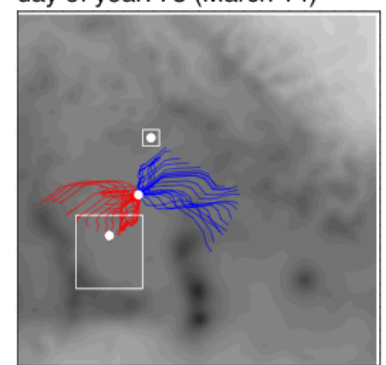

day of year: 77 (March 18)

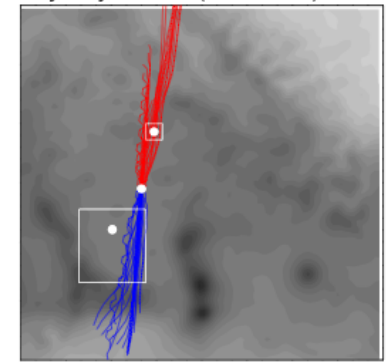

day of year: 81 (March 22)

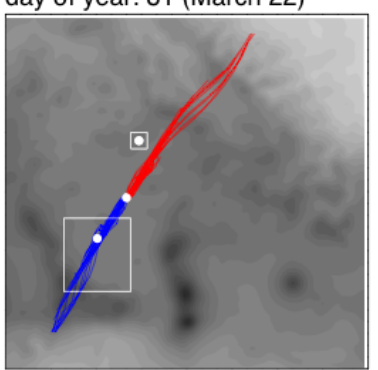

day of year: 85 (March 26)

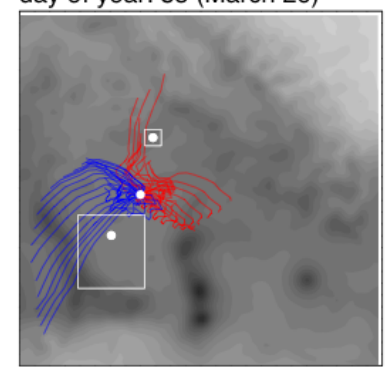

day of year: 70 (March 11)

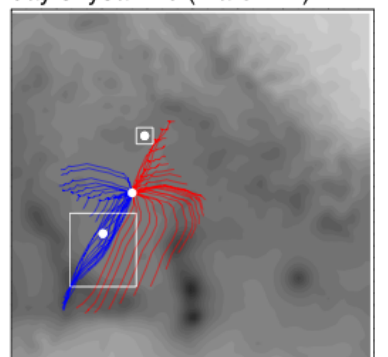

day of year: 74 (March 15)

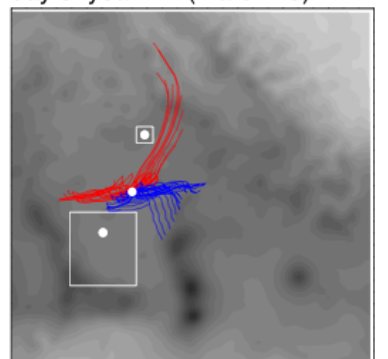

day of year: 78 (March 19)

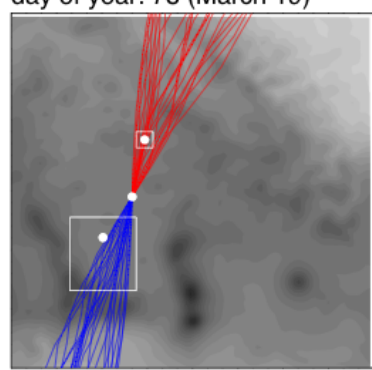

day of year: 82 (March 23)

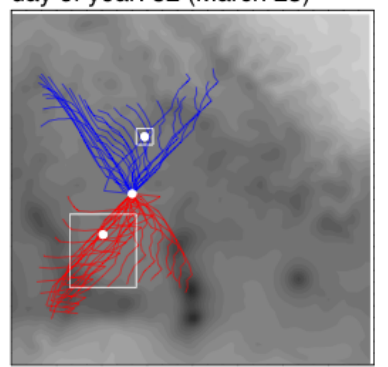

day of year: 86 (March 27)

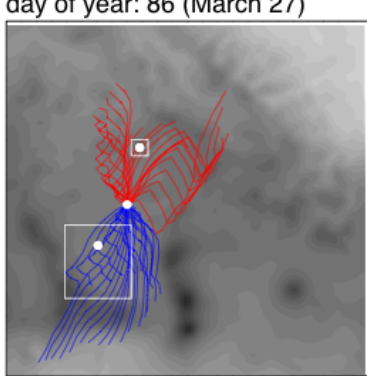

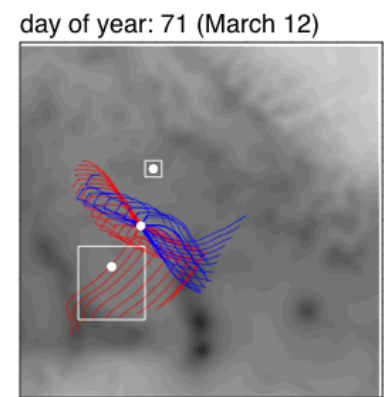

day of year: 75 (March 16)

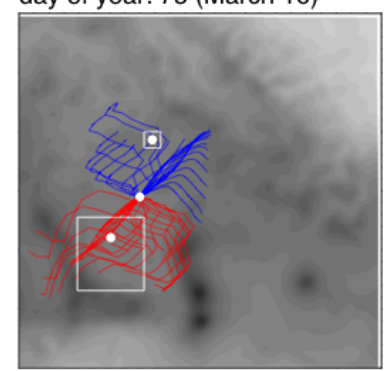

day of year: 79 (March 20)

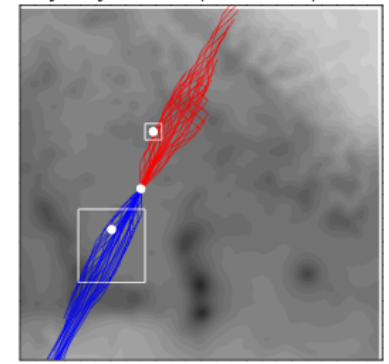

day of year: 83 (March 24)

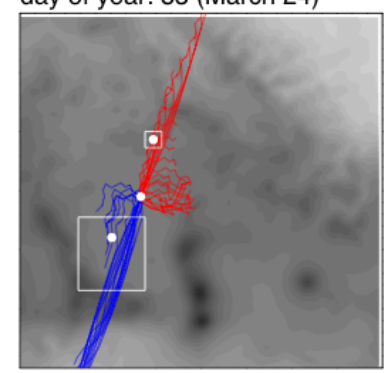

day of year: 87 (March 28)

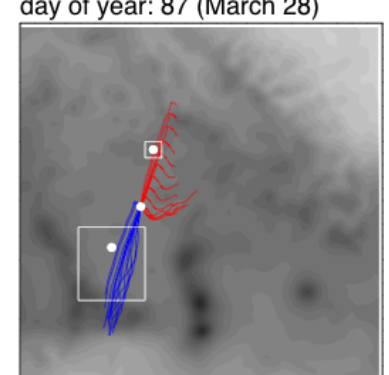

Fig. 4. Trajectories of air parcels passing over $\mathrm{T} 1$ at $1000 \mathrm{~m}$ a.g.l. for the hours 06:00-18:00 LST based on 30-min RWP data at T1. Blue indicates flow into T1 and red indicates flow away from T1. The small box around T2 is $10 \mathrm{~km}$ on a side; the larger box around T0 is an approximate boundary of Mexico City. 

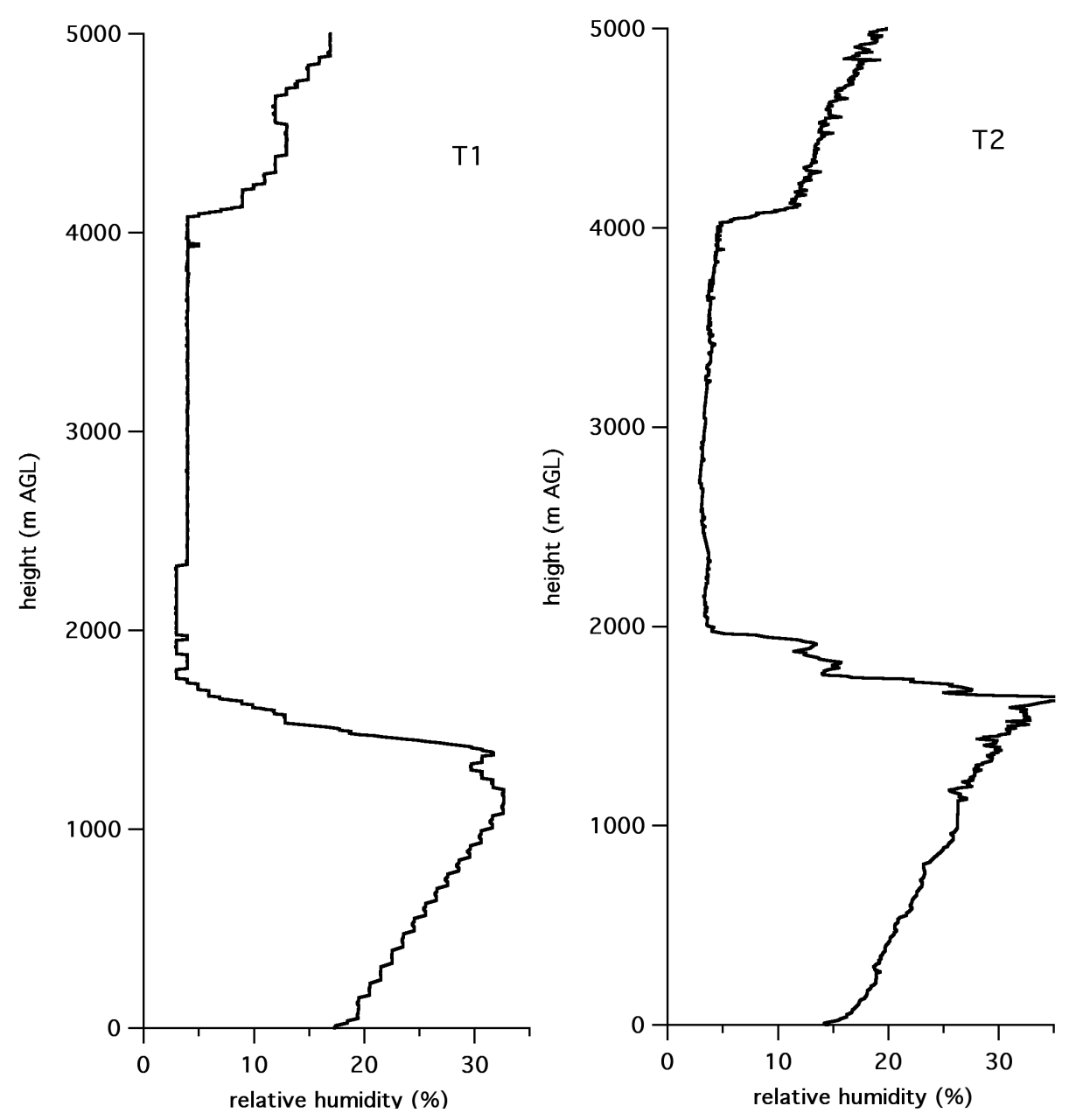

Fig. 5. Example of relative humidity profiles at $\mathrm{T} 1$ and $\mathrm{T} 2$ showing dry layer above the boundary layer for sounding taken at 13:00 LST on DOY 78 (19 March). The stair-step pattern at T1 is due to the limited resolution of the humidity measurements for the system deployed there.

the afternoon of DOY 83. The rain may have contributed to the lower carbon concentrations and the specific absorption values are somewhat higher than the median values found for other transport periods. While this is consistent with the results found by Redemann et al. (2001) and Mikhailov et al. (2006), the sampling period is rather small and we hesitate to attach too much significance to this result at this time.

There is considerable scatter about the means, but for the period shown in Fig. 6 the OC concentrations at T2 were approximately $23 \%$ lower than at T1 while the EC concentrations were smaller by almost a factor of four. The average $\mathrm{EC} / \mathrm{OC}$ ratio at $\mathrm{T} 1$ was 0.210 , while that at $\mathrm{T} 2$ was approximately three times smaller with a value of 0.063 . Assuming the Mexico City metropolitan area is the primary source of $\mathrm{EC}$ in the area, the decrease in this quantity between $\mathrm{T} 1$ and $\mathrm{T} 2$ was anticipated, given the dilution expected in traveling between the two sites. Conversely, the much smaller change in OC concentrations presumably reflects the rapid and ongoing generation of OC over the region (Volkamer et al., 2006).

\subsection{Specific absorption of EC}

There is still some debate about exactly what is measured by an OCEC analyzer. Andreae and Gelencsér (2006) propose an operational definition for apparent elemental carbon, as "the fraction of carbon that is oxidized above a certain temperature threshold in the presence of an oxygen-containing atmosphere", and denote this quantity as $\mathrm{EC}_{a}$. For simplicity in this paper we have retained the more commonly used designation EC, but we are mindful of this potentially important distinction. Under some circumstances EC may only be loosely related to soot particles, but the connection should be considerably better in regions with high concentrations of petroleum combustion sources, and Mexico City is one such region. Andreae and Gelencsér also note that $\mathrm{BC}$ is often used to denote the result of a light-absorbing carbon measurement by an optical absorption technique. In any event, our interest for this study was not the measurement of the specific absorption of soot per se but rather the absorption 

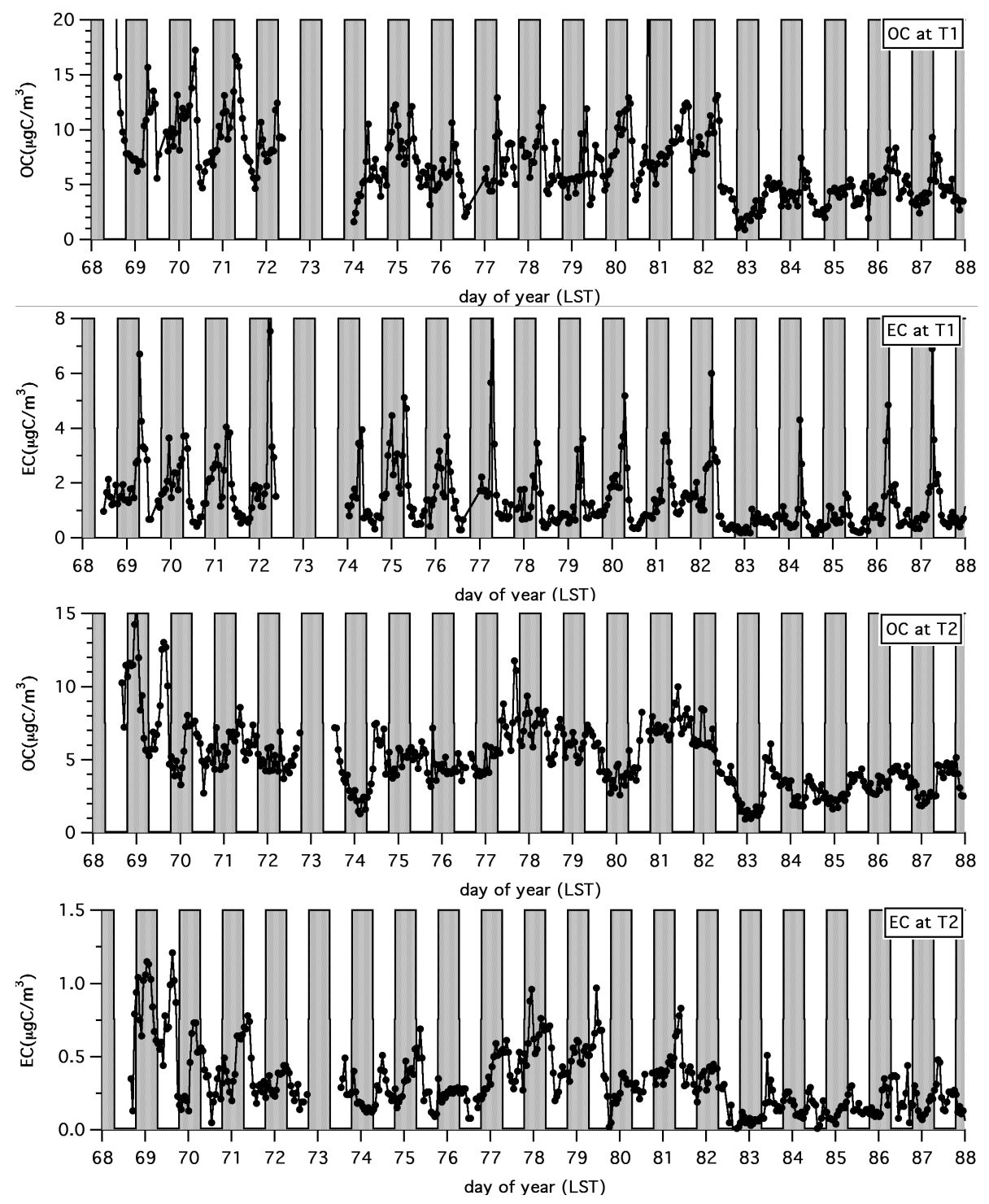

Fig. 6. Time series of the organic (OC) and elemental (EC) carbon concentrations at $\mathrm{T} 1$ and $\mathrm{T} 2$. Nighttime periods are indicated by the shaded areas. Note differences in scales for $\mathrm{T} 1$ and $\mathrm{T} 2$.

per unit mass of EC and how that may be modified as EC becomes coated in the hours or days after emission. We again note that almost all of the absorption measured by the PASs at $\mathrm{T} 1$ and $\mathrm{T} 2$ is likely due to the $\mathrm{EC}$ at the respective sites because dust and OC do not absorb significantly at the wavelength of the PAS measurements. Figure 7 shows time series of EC concentrations, absorption measured by the PASs, and specific absorption computed from the ratio of the absorption determined from the PASs and the EC concentrations measured by the OCEC analyzers, for a 12-day period during which the OCEC analyzers and PASs at both sites had good data recovery.

Figure 8 shows a scatter plot of the absorption as a function of EC concentrations at the two sites. There is a greater degree of scatter at T2 than at T1, which is expected given the substantially lower EC concentrations and absorption found at the former site. At T1 the EC concentrations and absorption values were as much as an order of magnitude higher than at $\mathrm{T} 2$ but the specific absorption was generally higher at $\mathrm{T} 2$ than at $\mathrm{T} 1$.

The figure shows that reasonably robust fits to the data at each site can be obtained with linear fits that are constrained to go through the origin. The $R^{2}$ values in each case are $\sim 0.96$. The slopes of the lines in the figure correspond to the mean values of specific absorption at the two sites, with the value at $\mathrm{T} 2$ about $9 \%$ higher than that at $\mathrm{T} 1$ for the full sampling period. One can also obtain a least squares fit to the data at each site while leaving the intercept as a free 

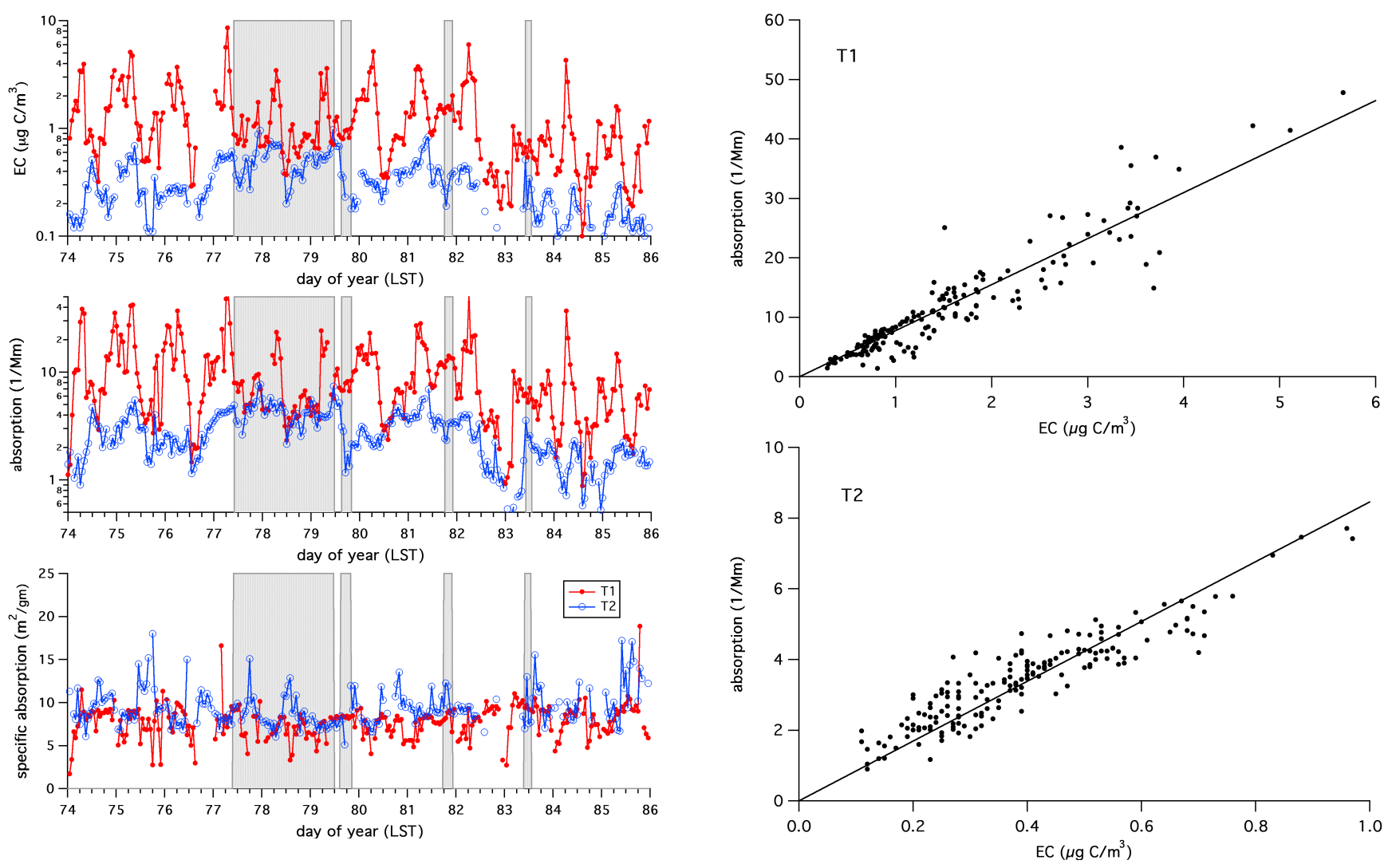

Fig. 7. Time series of EC concentrations, absorption measured by the PASs, and specific absorption of EC at T1 and T2 for a 12-day period during which the OCEC analyzers and PASs at both sites had good data recovery. Transport periods are indicated by the shaded areas.

parameter. The results are virtually unchanged at $\mathrm{T} 1$ but result in a smaller slope at $\mathrm{T} 2$ and an intercept on the order of $0.6 \mathrm{Mm}^{-1}$. A non-zero intercept is unphysical (if the EC concentration is zero the absorption should be zero) and may indicate errors in the measurements, another absorbing species, or that the specific absorption is not necessarily independent of concentration. At this time we have no way of distinguishing among these possibilities. Partly for this reason, and partly to mitigate the effects of possible outliers in the data, we prefer to use the median values of specific absorption at T1 and T2 rather than mean values. Moreover, given the skewed nature of the distributions of specific absorption shown in Fig. 9, we believe the median is a more useful indicator of the behavior than the mean.

Histograms of specific absorption at the two sites are shown in Fig. 9 and indicate that the distributions were skewed toward higher values at T2 but not at T1. This is what would be expected if the differences between the sites are attributable to the greater aging of the EC sampled at the site more distant from sources in Mexico City.

Fig. 8. Scatter plots of absorption as a function of EC concentration at T1 (top) and T2 (bottom). The straight lines are least squares fits to the data that are constrained to pass through the origin.

It is interesting to compare the values of specific absorption at the two sites during times when the Mexico City plume was traveling from the city over T1 and then T2 with the values found when such transport was not occurring. Using the T1 RWP data, we identified "transport" periods when air parcels passing through $\mathrm{T} 1$ were likely to have originated over the city and subsequently passed within $5 \mathrm{~km}$ of T2 approximately $4 \mathrm{~h}$ or less after exiting the city. In some cases near-surface trajectories did not have favorable directions but trajectories further aloft (e.g., $1 \mathrm{~km}$ ) did. If these cases occurred when a convective boundary layer was present that could mix air parcels throughout the boundary layer to the surface, then those periods were also included in the transport category. All other periods were lumped into the "nontransport" category. Without using a detailed mesoscale model constrained by data assimilation of RWP data there is some uncertainty and subjectivity in the choice of the particular time periods to include in each category, but our results are not especially sensitive to the details of the selection criteria. Table 1 gives median and 10th and 90th percentile values of the specific absorption at $\mathrm{T} 1$ and $\mathrm{T} 2$ for the transport and non-transport periods. We have also included values of 

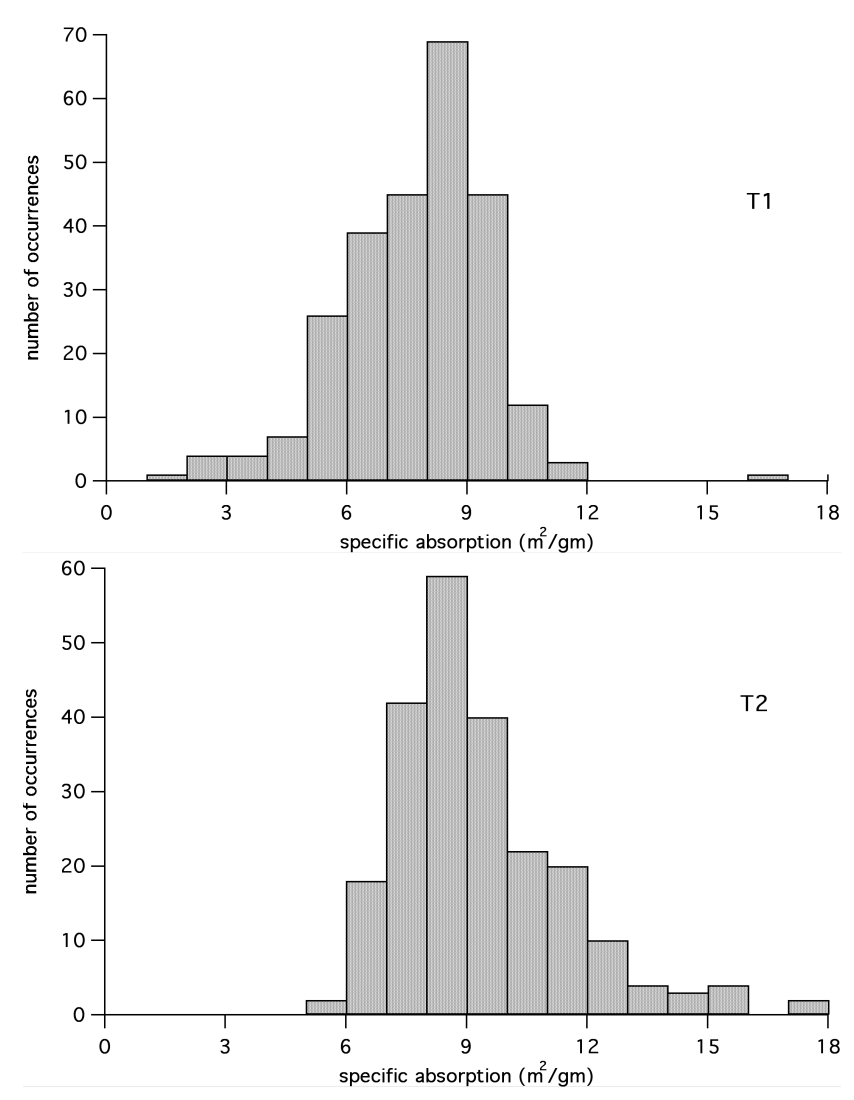

Fig. 9. Histograms of specific absorption of EC at $870 \mathrm{~nm}$ at T1 (top) and T2 (bottom). The histogram for T1 represents $264 \mathrm{~h}$ of data while that for $\mathrm{T} 2$ represents $236 \mathrm{~h}$.

specific absorption extrapolated to a wavelength of $550 \mathrm{~nm}$, assuming a $\lambda^{-1}$ dependence for the absorption between 870 and $550 \mathrm{~nm}$ as suggested by Bergstrom et al. (2002).

Two features stand out in the table. The first is that larger values of specific absorption are found at both $\mathrm{T} 1$ and $\mathrm{T} 2$ during non-transport times than during transport times. This is consistent with the expectation that longer-aged EC with greater coating is more likely to be found at both sites if the wind is not blowing directly from the city. The second feature is that the specific absorption at $\mathrm{T} 2$ is larger than at $\mathrm{T} 1$ for both transport and non-transport periods. This suggests that the specific absorption of EC can be modified after only a few hours of aging, the time required for transport from $\mathrm{T} 1$ to T2. On non-transport days the results indicate that fresher emissions from Mexico City or nearby local sources are still more likely to be found at T1 than at T2. Although the differences in specific absorption noted here are not large, a Mann-Whitney test indicates that the differences are statistically significant at the $1 \%$ level.

The median values extrapolated to $550 \mathrm{~nm}$ displayed in the table are considerably larger than the value of $7.5 \pm 1.2 \mathrm{~m}^{2} \mathrm{~g}^{-1}$ reported by Bond and Bergstrom (2006) for uncoated soot particles. However, Bond et al. (2006) suggest that absorption by aged aerosol is about 1.5 times greater than that of fresh aerosol at $550 \mathrm{~nm}$. Johnson et al. (2005) note that while in Mexico City "fresh particulate emissions from mixed-traffic are almost entirely carbonaceous... ambient soot particles which have been processed for less than a few hours are heavily internally mixed..." Our larger values of specific absorption are thus consistent with this characterization of the emissions.

It is interesting that the 10th percentile value of specific absorption at $\mathrm{T} 1$ during transport conditions is $8.7 \mathrm{~m}^{2} \mathrm{~g}^{-1}$ (extrapolated to $550 \mathrm{~nm}$ ), which is near the upper end of the range of values suggested by Bond and Bergstrom for freshly emitted soot. In contrast, the 10th percentile value of specific absorption at T2 is 10.8 , well beyond the suggested range. For non-transport periods, the 10th percentile value at $\mathrm{T} 1$ is still 8.7, which is consistent with our expectation that even during non-transport periods $\mathrm{T} 1$ would often be influenced by nearby sources. This is less likely to be the case at T2, and the 10th percentile value there is indeed substantially larger than for transport conditions.

The extrapolations of the specific absorption values from $870 \mathrm{~nm}$ to $550 \mathrm{~nm}$ shown in the table may be problematic. Bergstrom et al. (2002) found a $\sigma_{A} \sim \lambda^{-1}$ dependence, where $\sigma_{A}$ is the cross section for aerosol scattering, but Moosmüller et al. (1998) derived a $\lambda^{-2.7}$ relationship from their analysis. Using PSAP data at three wavelengths we have examined the wavelength dependence of absorption between 470 and $660 \mathrm{~nm}$. We found the median exponent in the expression $\sigma_{A} \sim \lambda^{b}$ is close to -1 , but there is considerable scatter about this value. Moreover, an extrapolation derived from 660 and $530 \mathrm{~nm}$ PSAP data cannot be applied with much confidence to the much larger extrapolation of the $870 \mathrm{~nm}$ photoacoustic results to $550 \mathrm{~nm}$. Thus we do not believe that a point-bypoint comparison of $530 \mathrm{~nm}$ PSAP and $870 \mathrm{~nm}$ PAS absorption values is warranted. The extrapolation of the summary statistics shown in the table may still be useful, but we suggest that the $550 \mathrm{~nm}$ values be treated with considerable caution.

The G-1 aircraft did not measure EC so it is not possible to use G-1 data to directly extract values of specific absorption as it passed through the Mexico City urban plumes.

\subsection{Single scattering albedo}

We have made an initial examination of the single scattering albedo determined from the airborne nephelometer and PSAP data to see if significant changes could be discerned between the $\mathrm{T} 1$ and $\mathrm{T} 2$ locations on days when the urban plume was carried over or near both sites. The single scattering albedo is defined by $\varpi_{0}=\frac{\Sigma_{S}}{\Sigma_{S}+\Sigma_{A}}$, where $\Sigma_{S}$ and $\Sigma_{A}$ are the extinction coefficients for aerosol scattering and absorption, respectively. Values of $\varpi_{0}$ were calculated when the G-1 was sampling within $5 \mathrm{~km}$ of $\mathrm{T} 1$ or T2 on DOY 77 , 78, and 79 (18, 19, and 20 March). From the PSAP and 
Table 1. Median, 10th and 90th percentile values of specific absorption of EC in $\mathrm{m}^{2} \mathrm{~g}^{-1}$ for transport and non-transport periods.

\begin{tabular}{|c|c|c|c|c|c|c|}
\hline & \multicolumn{3}{|c|}{$\mathrm{T} 1$} & \multicolumn{3}{|c|}{$\mathrm{T} 2$} \\
\hline & 10 th percentile & median & 90th percentile & 10th percentile & median & 90th percentile \\
\hline $\begin{array}{l}\text { transport peri- } \\
\text { ods } 870 \mathrm{~nm}\end{array}$ & 5.5 & 7.7 & 9.2 & 6.8 & 8.3 & 11.9 \\
\hline $\begin{array}{l}\text { non-transport } \\
\text { periods }\end{array}$ & 5.5 & 8.1 & 9.7 & 7.5 & 9.0 & 12.2 \\
\hline $\begin{array}{l}870 \mathrm{~nm} \\
\text { transport peri- } \\
\text { ods } 550 \mathrm{~nm}\end{array}$ & 8.7 & 12.2 & 14.5 & 10.8 & 13.1 & 18.8 \\
\hline $\begin{array}{l}\text { non-transport } \\
\text { periods } \\
550 \mathrm{~nm}\end{array}$ & 8.7 & 12.8 & 15.4 & 11.8 & 14.3 & 19.3 \\
\hline
\end{tabular}

Table 2. Mean values of $\varpi_{0}$ derived from the T1 and T2 MFRSRs (at $500 \mathrm{~nm}$ ) and from the T2 surface aerosol system (nephelometer and PSAP) data (at $530 \mathrm{~nm}$ ) for DOY 71, 78, and 86 (12, 19, and 27 March). Note that surface values were available only at T2.

\begin{tabular}{llllllll}
\hline DOY & Time (LST) & $\begin{array}{l}\varpi_{0} \text { from } \\
\text { MFRSR }\end{array}$ & $\begin{array}{l}\text { T1 } \\
\text { face system }\end{array}$ & $\begin{array}{l}\varpi_{0} \text { from T2 sur- } \\
\text { fime (LST) }\end{array}$ & $\begin{array}{l}\varpi_{0} \text { from } \\
\text { T2 MFRSR }\end{array}$ & $\begin{array}{l}\varpi_{0} \text { from T2 sur- } \\
\text { face system }\end{array}$ \\
\hline 71 & $08: 00-09: 36$ & 0.84 & 0.88 & $08: 00-09: 36$ & 0.91 & 0.88 \\
78 & $07: 30-09: 30$ & 0.85 & 0.92 & $07: 30-11: 28$ & 0.83 & 0.91 \\
86 & $08: 00-10: 00$ & 0.89 & 0.92 & $07: 30-08: 00$ & 0.90 & 0.90 \\
\hline
\end{tabular}

nephelometer data, $\varpi_{0}$ was on the order of 0.9 for most of the flights during these transport periods, so that $\sigma_{A} \sim \sigma_{S} / 9$. From Table 1, the median specific absorption at the surface at $\mathrm{T} 2$ was $\sim 10 \%$ larger than that at $\mathrm{T} 1$. We can assume that the variations in the surface absorption values were approximately the same as those at the G-1 sampling elevations because the boundary layer was generally well developed at the times of the G-1 overflights. Thus, reductions in $\varpi_{0}$ between $\mathrm{T} 1$ and $\mathrm{T} 2$ arising from changes in $\sigma_{A}$ (and assuming $\sigma_{S}$ was unchanged) would only be on the order of 0.01. Given the observed fluctuations in the values of $\varpi_{0}$, consistent differences between $\mathrm{T} 1$ and $\mathrm{T} 2$ were expected to be difficult to identify in the G-1's data stream (although such accuracy has been suggested as needed for climate studies (Heintzenberg et al., 1997)). This expectation was confirmed in our initial examination of the G-1 data time series. Further analyses are planned using CO measurements to help identify the times and locations when the G-1 was sampling within the Mexico City urban plume and to compare in-plume and out-of-plume values of $\varpi_{0}$, but at this point we do not anticipate major changes in $\varpi_{0}$ will be found between $\mathrm{T} 1$ and $\mathrm{T} 2$.

We have evaluated single scattering albedos at the surface at T2 for the transport and non-transport periods described above as well. The distributions of $\varpi_{0}$ for these two periods are similar, with mean values differing by approximately 0.01 or less. This implies that the direct radiative forcing at T2 should not be significantly affected by the differences in the specific absorption of EC between transport and nontransport periods, although it still could be affected by other factors such as variations in the total optical depth between the two sites. It would have been desirable to compare surface results from the $\mathrm{T} 1$ and $\mathrm{T} 2$ sites to see if those distributions of $\varpi_{0}$ were similar, but the data recovery for the nephleometer and PSAP at T1 was poor and we are unable to provide such a comparison at this time.

We have also used the MFRSR data at T1 and T2 to derive values for $\varpi_{0}$ at $500 \mathrm{~nm}$ using the approach described by Kassianov et al. (2005). In contrast to the aerosol quantities measured by our other surface instruments, $\varpi_{0}$ derived from the MFRSR data can be considered as an average over the atmospheric column. The approach is only applicable when the sky is essentially cloud-free. In practice this often limits our analysis periods to a few hours in the morning because cumulus clouds frequently developed in the late morning or afternoon. Initial results are similar to those obtained from the G-1 measurements described above, i.e., differences in $\varpi_{0}$ between $\mathrm{T} 1$ and $\mathrm{T} 2$ are small $(\sim 0.01-0.02)$ without an obvious tendency for values at one or the other site to be larger.

Table 2 shows some values of $\varpi_{0}$ for a wavelength of $500 \mathrm{~nm}$ obtained from the MFRSRs and from the T2 surface aerosol system at $530 \mathrm{~nm}$ on three days with cloud-free 
periods. The times of the MFRSR measurements are given in the table. The agreement between the column averaged values of $\varpi_{0}$ and the T2 surface value is good for DOY 86 (27 March), fair for DOY 71, and poorer on DOY 78 (19 March).

The discrepancy between MFRSR and surface values of $\varpi_{0}$ on DOY 78 may be due to boundary-layer structure and growth. The G-1 made measurements on that day between $\sim 10: 50$ and 12:00 LST and found values ranging from 0.87 to 0.90 over $\mathrm{T} 1$ and around 0.87 over T2. At T2 this result is an intermediate one between the surface value and the column-averaged value. The sampling height of the aircraft was $\sim 3100 \mathrm{~m}$ m.s.l., or approximately $830 \mathrm{~m}$ a.g.l. at $\mathrm{T} 1$ and $560 \mathrm{~m}$ a.g.1. at T2. This would have placed the G-1 within the growing boundary layer at heights of $\sim 0.5-0.7$ of the mixed layer depths estimated from RWP signal-to-noise values. It is thus reasonable to assume that the G-1 was sampling in a region where the aerosol mix was influenced by both near-surface aerosols, with higher values of $\varpi_{0}$ as indicated by the nephelometer and PSAP data, and aerosols entrained from aloft, with lower values of $\varpi_{0}$ as suggested by the MFRSR results. Later in the afternoon ( 17:00 LST) when the boundary layer was deeper, the G-1 was again over the $\mathrm{T} 2$ site and measured a value of 0.90 for $\varpi_{0}$, which agrees well with the corresponding surface value at that time of 0.92 .

\section{Summary}

We have carried out an experiment to investigate the evolution of aerosols and their optical properties downwind from Mexico City. Our focus has been on the specific absorption of black carbon and how that is affected as the aerosols age and become coated, changing from an externally to an internally mixed state. To accomplish this we deployed instruments at two sites, T1 and T2, to characterize the meteorology, solar radiation, aerosol light scattering and absorption, and $\mathrm{OC}$ and EC concentrations. An instrumented aircraft flew a number of missions over the two sites as well.

The purpose of this paper has been to provide an overview of the T1-T2 experiment and to present some preliminary results and highlights from that campaign. OC and EC values at $\mathrm{T} 1$ showed diurnal variations suggesting a buildup of more polluted air from nearby urban sources during the night and a subsequent dilution as the boundary layer grew the following morning. This behavior was not found at the more isolated T2 site but transport from Mexico City appeared to be a major factor in determining OC and EC concentrations. Using data from a radar wind profiler, we have divided the measurement periods into transport and non-transport periods, corresponding to conditions when air masses were or were not expected to travel from Mexico City and then over T1 and T2. The specific absorption of EC during transport periods was lower than that found during non-transport periods, which is consistent with the expectation that fresher emis- sions are more likely to be found at T1 and T2 during transport episodes than at other times. The specific absorption at $\mathrm{T} 2$, the site more distant from Mexico City, was also found to be larger than at T1, in keeping with the greater age of the aerosols expected at T2. Initial analyses of the variation of $\varpi_{0}$ at $\mathrm{T} 2$ for transport and non-transport periods reveal only small differences, although additional analyses are planned. Comparisons of values from G-1 aircraft data, surface optical measurements, and column-averaged values derived from MFRSR data appear broadly consistent, although boundarylayer structure and growth appear to contribute to some differences between the in situ and the column-averaged values.

A number of additional topics are anticipated for future studies, including detailed examination of the in-plume and out-of-plume aerosol characteristics derived from the G-1 measurements, more detailed analyses of plume trajectories and their relation to the specific absorption measured at $\mathrm{T} 1$ and $\mathrm{T} 2$, assessment of the aerosol optical characteristics at $\mathrm{T} 0$, and further comparisons of in situ and column-averaged aerosol properties.

Acknowledgements. We thank J. Ogren, B. Andrews, and P. Sheridan of NOAA's CMDL for their assistance with the construction of the aerosol optical measurement systems and the subsequent data processing. We appreciate the assistance of P. Holowecky and J. Satola of Battelle Columbus for their contributions to the field measurements. This research was supported by the Office of Science (BER), U.S. Department of Energy, under the auspices of the Atmospheric Science Program, under Contract DE-AC0576RL01830 at the Pacific Northwest National Laboratory. Pacific Northwest National Laboratory is operated for the U.S. DOE by Battelle Memorial Institute.

Edited by: S. Madronich

\section{References}

Anderson, T. L. and Ogren, J. A.: Determining aerosol radiative properties using the TSI 3563 Integrating Nephelometer, Aerosol Sci. Technol., 29, 57-69, 1998.

Andreae, M. O. and Gelencsér, A.: Black carbon or brown carbon? The nature of light-absorbing aerosols, Atmos. Chem. Phys., 6, 3131-3148, 2006, http://www.atmos-chem-phys.net/6/3131/2006/.

Arnott, W. P., Moosmüller, H., Sheridan, P. J., Ogren, J. A., Raspert, R., Slaton, W. V., Hand, J. L., Kreidenweis, S. M., and Collett Jr., J. L.: Photoacoustic and filter-based ambient aerosol light absorption measurements: instrument comparisons and the role of relative humidity, J. Geophys. Res., 108, 4034, doi:10.1029/2002JD002165, 2003.

Baumgardner, D., Raga, G. B., Kok, G., Ogren, J., Rosas, I., Báez, A., and Novakov, T.: On the evolution of aerosol properties at a mountain site above Mexico City, J. Geophys. Res., 105, $22243-$ $22253,2000$.

Baumgardner, D. and Clarke, A.: Changes in aerosol properties with relative humidity in the remote southern hemisphere ma- 
rine boundary layer, J. Geophys. Res., 103(D13), 16 525-16 534, doi:10.1029/98JD00688, 1998.

Baumgardner, D., Raga, G., Peralta, O., Rosas, I., Castro, T., Kuhlbusch, T., John, A., and Petzold, A.: Diagnosing black carbon trends in large urban areas using carbon monoxide measurements, J. Geophys. Res., 107(D21), 8342, doi:10.1029/2001JD000626, 2002.

Birch, M. E. and Cary, R. A.: Elemental carbon-based method for monitoring occupational exposures to particulate diesel exhaust, Aerosol Sci. Technol., 25, 221-241, 1996.

Bond, T. C., Anderson, T. L., and Campbell, D.: Calibration and intercomparison of filter-based measurements of visible light absorption by aerosols, Aerosol Sci. Technol., 30, 582-600, 1999.

Bond, T. C. and Bergstrom, R. W.: Light absorption by carbonaceous particles: an investigative review. Aerosol Sci. Technol., 40, 27-67, doi:10.1080/02786820500421521, 2006.

Bond., T. C., Habib, G., and Bergstrom, R. W.: Limitations in the enhancement of visible light absorption due to mixing state, J. Geophys. Res., 111, D20211, doi:10.1029/2006JD007315, 2006.

Carrico, C. M., Kus, P., Rood, M. J., Quinn, P. K., and Bates, T. S.: Mixtures of pollution, dust, sea salt, and volcanic aerosol during ACE-Asia: Radiative properties as a function of relative humidity, J. Geophys. Res., 108(D23), 8650, doi:10.1029/2003JD003405, 2003.

Chung, S. H. and Seinfeld, J. H.: Global distribution and climate forcing of carbonaceous aerosols, J. Geophys. Res., 107(D19), 4407, doi:10.1029/2001JD001397, 2002.

Doran, J. C., Abbott, J. L., Archuleta, J., Bian, X., Chow, J. C., Coulter, R. L., de Wekker, S. F. J., Edgerton, S. A., Fernandez, A., Fast, J. D., Hubbe, J. M., King, C. W., Langley, D., Leach, J. M., Lee, J. T., Martin, T. J., Martinez, D., Martinez, J. L., Mercado, G., Mora, V., Mulhearn, M., Pena, J. L., Petty, R., Porch, W. M., Russell, C., Salas, R., Shannon, J. D., Shaw, W. J., Sosa, G., Watson, J. G., Templeman, B., White, R., Whiteman, C. D., and Wolfe, D.: The IMADA-AVER boundary layer experiment in the Mexico City area, Bull. Am. Meteorol. Soc., 79, $2497-$ 2508, 1998

Fuller, K. A., Malm, W. C., and Kreidenweis, S. M.: Effects of mixing on extinction by carbonaceous particles, J. Geophys., Res., 104, 15 941-15 954, 1999.

Harrison, L., Michalsky, J., and Berndt, J.: Automated multifilter rotating shadow-band radiometer: an instrument for optical depth and radiation measurements, Appl. Opt., 33, 5118-5125, 1994.

Heintzenberg, J., Charlson, R. J., Clarke, A. D., Liousse, C., Ramaswamy, V., Shine, K. P., Wendisch, M., and Helas, G.: Measurements and modeling of aerosol single-scattering albedo: Progress, problems, and prospects, Beitr. Phys. Atmosph., 70, 249-263, 1997.

Horvath, H.: Atmospheric light absorption - A review, Atmos. Environ., 27A(3), 293-317, 1993

Im, J.-S., Saxena, V. K., and Wenny, B. N.: An assessment of hygroscopic growth factors for aerosols in the surface boundary layer for computing direct radiative forcing, J. Geophys. Res., 106(D17), 20 213-20 224, doi:10.1029/2000JD000152, 2001.

Jacobson, M. Z.: Isolating nitrated and aromatic aerosols and nitrated aromatic gases as sources of ultraviolet light absorption, J. Geophys. Res.-A, 104(D3), 3527-3542, 1999.

Jacobson, M. Z.:. Strong radiative heating due to the mixing state of black carbon in atmospheric aerosols, Nature, 409, 695-696, 2001.

Jacobson, M. Z. and Seinfeld, J. H.: Evolution of nanoparticle size and mixing state near the point of emission, Atmos. Environ., 38, 1839-1850, 2004

Johnson, K. S., Zuberi, B., Molina, L. T., Molina, M. J., Iedema, M. J., Cowin, J. P., Gaspar, D. J., Wang, C., and Laskin, A.: Processing of soot in an urban environment: case study from the Mexico City Metropolitan Area, Atmos. Chem. Phys., 5, 30333043, 2005, http://www.atmos-chem-phys.net/5/3033/2005/.

Kassianov, E., Barnard, J., and Ackerman, T. P.: Retrieval of aerosol microphysical properties using surface multifilter rotating shadowband radiometer (MFRSR) data: modeling and observations, J. Geophys. Res., 110, D09201, doi:10.1029/2004JD005337, 2005.

Kirchstetter, T. W., Novakov, T., and Hobbs, P. V.: Evidence that the spectral dependence of light absorption by aerosols is affected by organic carbon, J. Geophys. Res.-A, 109, D21208, doi:10.1029/2004JD004999, 2004.

Liousse, C., Cachier, H., and Jennings, S. G.: Optical and thermal measurements of black carbon aerosol content in different environments: variation of the specific attenuation cross-section, sigma $(\sigma)$, Atmos. Environ., 27A, 1203-1211, 1993.

Mallet, M., Roger, J. C., Despiau, S., Dubovik, O., and Putaud, J. P.: Microphysical and optical properties of aerosol particles in urban zone during ESCOMPTE, Atmos. Res., 69, 73-97, 2003.

Markowicz, K. M., Flatau, P. J., Quinn, P. K., Carrico, C. M., Flatau, M. K., Vogelmann, A. M., Bates, D., Liu, M., and Rood, M. J.: Influence of relative humidity on aerosol radiative forcing: An ACE-Asia experiment perspective, J. Geophys. Res., 108(D23), 8662, doi:10.1029/2002JD003066, 2003.

Marley, N. A., Gaffney, J. S., Baird, C., Blazer, C. A., Drayton, P. J., and Frederick, J. E.: An empirical method for the determination of the complex refractive index of size-fractionated atmospheric aerosols for radiative transfer calculations, Aerosol Sci. Technol., 34(6), 535-549, 2001.

Mikhailov, E. F., Vlasenko, S. S., Podgorny, I. A., Ramanathan, V., and Corrigan, C. E.: Optical properties of soot-water drop agglomerates: an experimental study, J. Geophys. Res., 111, D07209, doi:10.1029/2005JD006389, 2006

Moosmüller, H., Arnott, W. P., Rogers, C. F., Chow, J. C., Frazier, C. A., Sherman, L. E., and Dietrich, D. L.: Photoacoustic and filter measurements related to aerosol light absorption during the Northern Front Range Air Quality Study (Colorado 1996/1997), J. Geophys. Res., 103(D21), 28 149-28 157, 1998.

Morse, C. S., Goodrich, R. K., and Cornman, L. B.: The NIMA method for improved moment estimation from Doppler spectra, J. Atmos. Oceanic Technol., 19, 274-295, 2002.

Nemesure, S., Wagener, R., and Schwartz, S. E.: Direct shortwave forcing of climate by the anthropogenic sulfate aerosol: sensitivity to particle size, composition, and relative humidity, J. Geophys. Res., 100(D12), 26 105-26 116, doi:10.1029/95JD02897, 1995.

Penner, J. E, Chang, C. C., and Grant, K.: Climate forcing by carbonaceous and sulfate aerosols, Clim. Dyn., 14, 839-851, 1998.

Petzold, A., Kopp, C., and Niessner, R.: The dependence of the specific attenuation cross-section on black carbon mass fraction and particle size, Atmos. Environ., 35(5), 661-672, 1997. 
Redemann, J., Russell, P. B., and Hamill, P.: Dependence of aerosol light absorption and single-scattering albedo on ambient relative humidity for sulfate aerosols with black carbon cores, J. Geophys. Res., 106(D21), 27 487-27496, doi:10.1029/2001JD900231, 2001.

Sato, M., Hansen, J., Koch, D., Lacis, A., Ruedy, R., Dubovik, O., Holben, B., Chin, M., and Novakov, T.: Global atmospheric black carbon inferred from AERONET, Proc. Natl. Acad. Sci., 100, 6319-6324, 2003.

Schnaiter, M., Horvath, H., Möhler, O., Naumann, K.-H., Saathoff, H., and Schöck, O. W.: UV-VIS-NIR spectral optical properties of soot and soot-containing aerosols, J. Aerosol Sci., 34, 14211444, 2003.

Schuster, G. L., Dubovik, O., Holben, B. N., and Clothiaux, E. C.: Inferring black carbon content and specific absorption from Aerosol Robotic Network (AERONET) aerosol retrievals, J. Geophys. Res., 110, D10S17, doi:10.1029/2004JD004548, 2005 .
Sokolik, I. N. and Toon, O. B.: Incorporation of mineralogical composition of aerosols into models of radiative properties of mineral aerosol from the UV to IR wavelengths, J. Geophys. Res.-A, 104(D8), 9423-9444, 1999.

Volkamer, R., Jimenez, J. L., San Martini, F., Dzepina, K., Zhang, Q., Salcedo, D., Molina, L. T., Worsnop, D. R., and Molina, M. J.: Secondary organic aerosol Formation from anthropogenic air pollution: rapid and higher than expected, Geophys. Res. Lett., 33, L17811, doi:10.1029/2006GL026899, 2006.

Waggoner, A. P., Weiss, R. E., Ahlquist, N. C., Covert, D. S., Will, S., and Charlson, R. J.: Optical characteristics of atmospheric aerosols, Atmos. Environ., 15, 1891-1909, 1981. 